\title{
Morphological Evolution of ZnO Thin Films Deposited by Reactive Sputtering
}

\author{
Eugenia Mirica, ${ }^{\dagger}$ Glen Kowach, ${ }^{\ddagger}$ Paul Evans, ${ }^{\S}$ and Henry Du, ${ }^{* \dagger}$ \\ Department of Chemical, Biochemical and Materials Engineering, \\ Stevens I nstitute of Technol ogy, Hoboken, New J ersey 07030, Bell Laboratories, \\ Lucent Technologies, Murray Hill, New J ersey 07974, and Materials Science Department, \\ University of Wisconsin-Madison, Madison, Wisconsin 53706
}

Received October 4, 2002; Revised Manuscript Received J uly 2, 2003

\begin{abstract}
The morphological evolution of $\mathrm{ZnO}$ thin films deposited by magnetron sputtering has been investigated on two types of substrates, (111) textured Pt and (100) Si possessing a native oxide. The ZnO films are oriented with the c-axis [0001] normal to the substrate and possess varying degrees of crystallinity. The films have a columnar structure with column diameters in the range of $40-300 \mathrm{~nm}$. As observed by field emission scanning electron microscopy (FESEM), transmission electron microscopy (TEM), and X-ray diffraction, the film microstructure is strongly dependent on substrate temperature during deposition in the range from near room temperature up to 700 ${ }^{\circ} \mathrm{C}$ and is also dependent on substrate type. A textured film of platinum promotes nucleation thereby improving the crystallinity and texture of sputtered ZnO films. A mechanism for morphological evolution of the films via surface diffusion is proposed based on atom mobilities.
\end{abstract}

\section{Introduction}

The morphological evolution during the deposition of thin films has captured the interest of the thin film community due to the strong dependence of physical properties on microstructure, which in turn is strongly dependent on deposition conditions. The microstructure of a thin film deposited by physical vapor deposition depends on a number of factors including deposition rate, substrate-target distance, substrate temperature, substrate roughness, total pressure, and substrate type. Zinc oxide $(\mathrm{ZnO})$ thin films have been extensively studied for a variety of applications due to their unique combination of electrical, optical, and piezoelectric properties. These applications include the following: liquid crystal displays and window coatings, ${ }^{1}$ optical waveguides, ${ }^{2}$ gas sensors, ${ }^{3}$ heat mirrors for energy saving, ${ }^{4}$ solar cells, ${ }^{5}$ optoelectronic devices, ${ }^{6}$ lasers, ${ }^{7}$ ultraviolet/violet light emitting diodes (LEDs), ${ }^{8}$ surface acoustic wave devices (SAW), ${ }^{9}$ microel ectro mechanical systems (MEMS), ${ }^{10}$ and ultrasonic transducers. ${ }^{11}$

The ultimate purpose of this research project is to investigate the potential use of $\mathrm{ZnO}$ as the active piezoel ectric film for thin film resonator (TFR) devices as band-pass filters in wirel ess communication systems. In particular, ZnO is a promising alternative to AIN due to its higher electromechanical coupling coefficient thus offering a broader bandwidth ( $\mathrm{k}_{33}$ is $10-20 \%$ higher for $\mathrm{ZnO}$ as compared to AIN ${ }^{12,13}$ ). Resonators with a larger bandwidth allow higher data transfer rates in wireless networks; for example, ZnO would be suitable in global system for mobile communications (GSM) networks.

Sputtering is an excellent deposition technique for these films because it produces textured films (i.e., films that possess a preferred crystallographic orientation).

* Corresponding author. E-mail: hdu@stevens-tech.edu. Tel: (201) 216-5262. Fax: (201) 216-8306.

+ Stevens Institute of Technology.

¥ Lucent Technologies.

$\S$ University of Wisconsin-Madison
Sputtered ZnO films are typically c-axis-oriented normal to the substrate surface. However, due to the nonequilibrium nature of sputtering processes, the properties of the deposited films depend strongly on processing parameters. Although there has been a continuing effort in improving the quality of oriented $\mathrm{ZnO}$ for various applications, there is still a need for a systematic study of morphological evolution of the film under various deposition conditions and its effect on film properties.

There have been reported attempts to determine the crystal growth mechanism of $\mathrm{ZnO}$ thin films by observing the interfacial film-substrate microstructure for a number of different substrates. Interestingly, an amorphous $\mathrm{ZnO}$ layer was found at the $\mathrm{ZnO} / \mathrm{gl}$ ass and $\mathrm{ZnO} /$ Al interface ${ }^{14}$ due to the amorphous nature of gl ass and the native oxide of Al, respectively. Further polycrystalline growth is observed due to the self-nucleation of crystalline $\mathrm{ZnO}$ on the amorphous $\mathrm{ZnO}$ interface. However, no such amorphous layer was observed at $\mathrm{ZnO} /$ $\mathrm{Au}$ and $\mathrm{ZnO} /$ sapphire interfaces. ${ }^{14}$ Instead, an epitaxial orientation of c-axis $\mathrm{ZnO}$ is formed on these two substrates. Island growth has been proposed as the growth mechanism of $\mathrm{ZnO}$ at thicknesses below approximately $100 \AA .{ }^{15}$ Above this thickness, the growth mode changes due to stress relaxation from lattice mismatch by subgrain boundaries, which results in an improved orientation of the film. Verghese and Clarke ${ }^{16}$ explained the texturing mechanism of $\mathrm{ZnO}$ films deposited by the pulsed laser ablation method as a consequence of the nucleation of c-oriented grains that grow geometrically and impinge laterally by growth in [1010] directions. In an effort to limit the scope, this paper will not discuss morphological evolution of $\mathrm{ZnO}$ thin films without c-axis texture.

This paper will focus on $\mathrm{ZnO}$ films deposited on $\mathrm{Pt}$ on amorphous $\mathrm{SiO}_{2}$ since this substrate is the most relevant to the devices of interest, namely, solidly mounted resonator devices (SMR). SMR devices are 
Table 1. Summary of Parameters for RF (13.56 MHz) Sputtering Deposition of ZnO Thin Films

\begin{tabular}{ll}
\hline \multicolumn{1}{c}{ target material } & \multicolumn{1}{c}{$\mathrm{Zn}^{\mathrm{a}}$} \\
\hline deposition pressure & $0.7(\mathrm{~Pa})$ \\
base pressure & $<7 \times 10^{-4}(\mathrm{~Pa})$ \\
$\mathrm{Ar}: \mathrm{O}_{2}$ & $1: 1$ and $5 \mathrm{sccm}$ flow rate for both gases \\
substrate temperature & room temperature $-700{ }^{\circ} \mathrm{C}$ \\
substrate-target distance & $0.095 \mathrm{~m}$ \\
power (incident - reflected) & between 65 and $80 \mathrm{~W}$ \\
deposition rate & $2500-4000(\AA / \mathrm{h})$ \\
substrate types & $\mathrm{Pt}(111) 1000 \AA /$ therm. $\mathrm{SiO}_{2} 2000 \AA / \mathrm{Si}(100)$ \\
& $\mathrm{Pt} \mathrm{(111)} 1000 \AA / \mathrm{Ti} 100 \AA /$ therm. SiO $4000 \AA / \mathrm{Si}(100)$ \\
& $\mathrm{Pt}(111) 1000 \AA / \mathrm{Ti} 100 \AA /$ therm. SiO $2000 \AA / \mathrm{Si}(100)$
\end{tabular}

a 99.995\% PURE TECH Inc., $7.62 \mathrm{~cm}$ diameter and $0.32 \mathrm{~cm}$ thickness. ${ }^{\mathrm{b}}$ Possessing native oxide.

designed with the active piezoelectric film having top and bottom electrodes above an acoustic Bragg reflecting stack. This stack is comprised of alternating layers of materials having a large difference in acoustic impedance. For our devices, this stack is composed of amorphous $\mathrm{SiO}_{2}$ and poorly crystalline AIN layers with the topmost layer being $\mathrm{SiO}_{2}$. Therefore, we must grow an oriented crystalline ZnO film on an amorphous surface. This is overcome by nucleation on textured (111) Pt, which also acts as the bottom el ectrode.

Optimizing the piezoelectric response (i.e., el ectromechanical coupling coefficient) can be achieved by the fabrication of highly crystalline and textured thin films with minimal surface roughness, high resistivity, high dielectric breakdown strength, and low insertion loss (in general, insertion loss specifications of less than 1 $\mathrm{dB}$ are desired for front-end filters). Therefore, the critical challenges in optimizing $\mathrm{ZnO}$ films for this application lie in the control of texture, crystallinity, roughness, and film resistivity. Among these, the attention in this study will be directed toward the first two aspects, with emphasis on morphological evol ution of $\mathrm{ZnO}$ films grown by reactive sputtering at different substrate temperatures during the deposition on two types of nucleation substrates, (111) textured Pt and (100) Si possessing a native oxide.

\section{Experimental Procedures}

Zinc oxide $(\mathrm{ZnO})$ thin films were deposited by reactive sputtering using radi o frequency $(13.56 \mathrm{MHz})$ planar magnetron sputtering (ANELVA SPF-332H) in a sputtering-down geometry. High purity $\mathrm{Ar}$ and $\mathrm{O}_{2}$ were premixed and introduced into the system. B efore deposition onto the substrates, the target was presputtered for $10 \mathrm{~min}$. The substrate temperature was measured with a thermocouple situated in contact with the back of the substrate. Typically, $2 \mathrm{~h}$ deposition runs were employed for thin films of $\mathrm{ZnO}$ prepared in this study. The deposition parameters are summarized in Table 1. The platinum and titanium films on substrates listed in Table 1 were deposited by sputtering. The platinum films exhibited a (111) texture having a broad rocking curve with a full-width half-maximum of approximately $7^{\circ}$.

Deposited films were characterized using several techniques. X-ray diffraction ( $\theta-2 \theta$ scan) was performed using a Bragg-Brentano geometry with a CuK $\alpha$ X-ray source (1.5406 $\AA$ wavelength), graphite monochromator, and scintillation detector to study the crystallinity and the degree of preferred orientation of sputtered ZnO films; small slits were used to obtain high resolution as observed by fwhm $(2 \theta)$ for the $K_{\alpha 1}$ (400) Si peak of $0.052^{\circ}$. Texture data were obtained at the National Institute of Standards and Technology (NIST) with $\theta-2 \theta$ scans (Bragg-Brentano) and $\theta$ scans using a Siemens D500 diffractometer equipped with a focusing Ge incident monochromator tuned to $\mathrm{CuK}_{\alpha 1}$ radiation ${ }^{17}$. However, mono- chromatic radiation is not required for this technique. The texture measurement involved the collection of a $\theta-2 \theta$ scan (Bragg-Brentano) and $\theta$ scan from the specimen. Typically, fixed incident slit geometry was used in the experiments, as opposed to fixed irradiated geometry ( $\theta$-compensating slits). The technique requires that the divergence of the incident beam be the same for both scans and accurately known and that the final slit size be the same for both scans; both scans were collected with $0.23^{\circ}$ incident and $0.15^{\circ}$ receiving slits. No anti-scatter slits are placed on the detector side of the diffractometer as they intercept X-rays diffracted from a specimen tilted out of the symmetric position (i.e., during a $\theta$ scan) and affect the recorded intensities. The presence in the beam path of Soller slits parallel to the diffraction plane does not affect the measurement beyond reducing the intensity. The texture profile was determined from the $\theta-2 \theta$ scan and $\theta$ scan, or rocking curve, using TexturePlus, ${ }^{18}$ which corrects for defocusing, absorption, and variation in the irradiated area; ${ }^{19}$ in addition, a detector linearity correction was applied. Thus, the term texture profile is used to describe the corrected rocking curve.

The morphology of the films was investigated using a LEO 1530 fiel d emission scanning electron microscope (FESE M) in both plan and cross-section views. A detailed description of the microstructure and the presence of defects in the $\mathrm{ZnO}$ films were carried out by transmission electron microscopy (TEM) on cross-sections of selected films using a Phillips CM 20 field emission gun electron microscope operating at $200 \mathrm{kV}$. The samples were prepared by sandwiching with epoxy two pieces of specimen with the ZnO film sides facing each other. Thinning of the samples was done by tripod mechanical polishing followed by argon ion milling.

\section{Results and Discussion}

The purpose of this research is to determine the optimal deposition conditions for piezoelectric $\mathrm{ZnO}$ thin films. The ideal film would be an atomically smooth, stoichiometric, single-crystal grown on a bottom electrode that has a high el ectrical conductivity. However, due to the roughness of the acoustic reflector and the lack of a lattice-matched substrate, the best film attainable would be polycrystalline with a high degree of preferential orientation (texture). Therefore, the determination of the morphological evolution is of critical importance. In this section, we will discuss the crystallinity, preferred orientation, and morphology as observed by X-ray diffraction, electron microscopy, and electron diffraction. X-ray diffraction (XRD), specifically, integrated intensity of the 0002 and 0004 reflections and the rocking curve give a preliminary measure of the $\mathrm{ZnO}$ film quality. The $\theta-2 \theta$ XRD data for ZnO films deposited on both types of nucl eation substrates used in this study, namely, (111) textured Pt and (100) Si with native oxide, show a strong reflection from 0002 crystallographic planes and no intensity from $10 \overline{1} 0$ or $10 \overline{1} 1$. 


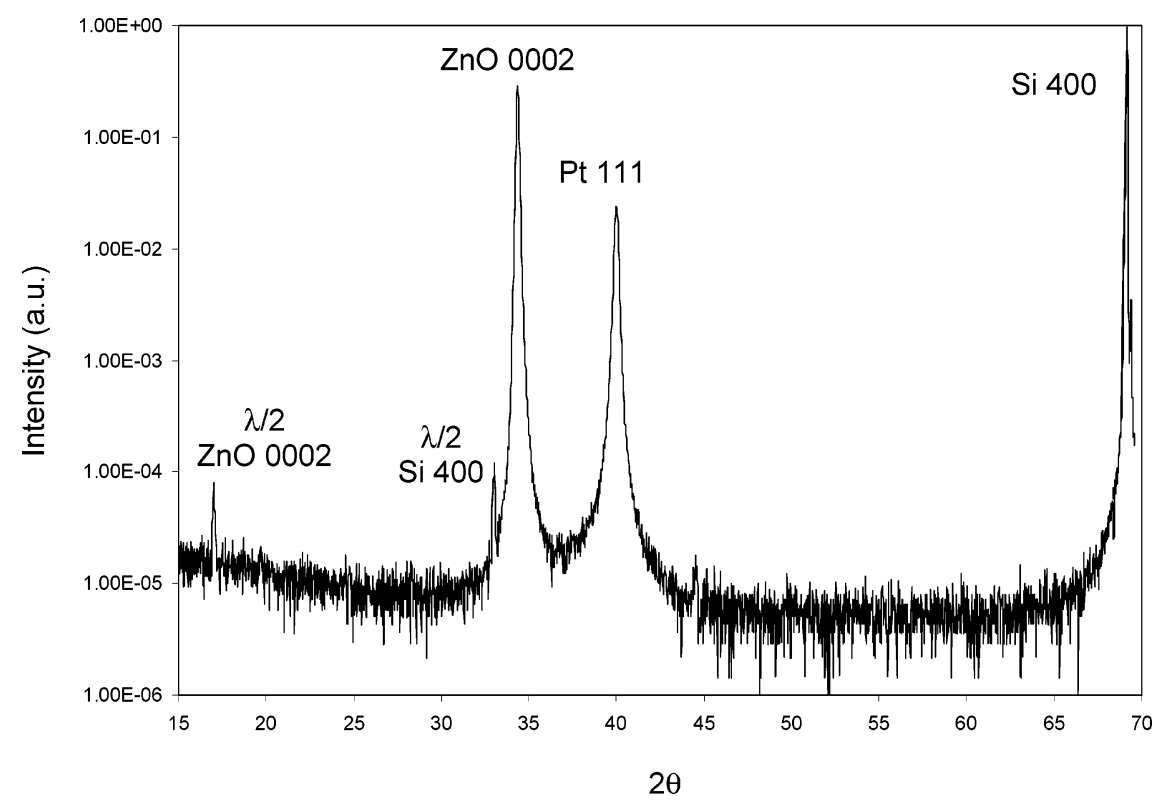

Figure 1. XRD spectrum for ZnO thin film deposited at $600{ }^{\circ} \mathrm{C}$ on (111) textured Pt. The only reflection from ZnO is 0002 , which demonstrates a high degree of preferred orientation (texture). Reflections corresponding to $\lambda / 2$ of the 400 reflection of $\mathrm{Si}$ and of the 0002 reflection of $\mathrm{ZnO}$ were confirmed by determining the energies of the detected photons. Note the intensity is plotted on a logarithmic scale.

These results demonstrate that the $\mathrm{ZnO}$ films are oriented with the c-axis normal to the substrate. Shown in Figure 1 is the $\mathrm{X}$-ray diffraction spectrum for $\mathrm{ZnO}$ film deposited at $600{ }^{\circ} \mathrm{C}$ on (111) textured $\mathrm{Pt} / \mathrm{SiO}_{2} / \mathrm{Si}$. Note the intense 111 Pt peak and no other Pt peaks, which indicates the strong texture of the Pt.

The degree of preferred orientation of a film with fiber texture is usually defined by the line width of the rocking curve in XRD $\theta$ scan. The 0002 rocking curve, reported as the corrected full width at half-maximum (fwhm), of the peak is $1.37^{\circ}$ for the film deposited at $650{ }^{\circ} \mathrm{C}$. The optics of the diffractometer mentioned earlier are important to include when reporting the rocking curve since the rocking curve fwhm may be influenced by beam divergence. A partial pole figure confirmed fiber texture in the films.

The variation of film morphology and texture with deposition temperature were examined using FESEM. The series of FESEM images presented in Figure 2 agree with the XRD data and indicate dense and highly oriented films. However, some distinct trends were reveal ed. Films deposited at higher temperatures (600 and $650^{\circ} \mathrm{C}$ ) show a smoother top surface and a higher density in cross-section as compared with those deposited at lower temperatures $\left(100-300^{\circ} \mathrm{C}\right)$. Films deposited at lower temperatures show finer grains and a columnar structure oriented normal to the substrate. The column width (lateral grain size) is approximately 20-30 nm, and the column length is the same as the film thickness. At $400{ }^{\circ} \mathrm{C}$, the grain morphology and size are nonuniform with grains having an average diameter of $50-60 \mathrm{~nm}$ surrounded by grains with an average diameter of approximately $300 \mathrm{~nm}$. At $550{ }^{\circ} \mathrm{C}$ (Figure $\left.2 \mathrm{~d}, \mathrm{~d}^{\prime}\right)$, the film surface looks much rougher, and the lateral grain size is about $150-200 \mathrm{~nm}$. The grain boundaries are easily identified from the surface morphology; however, the boundaries are not as easily identified in cross-section likely due to intragranular fracture during cleavage since grain boundaries are not visible when the fracture surface traverses within a grain. The increased surface roughness is due to faceting, which apparently reaches nearly complete termination, a fully developed hexagonal pyramidal geometry, at $550{ }^{\circ} \mathrm{C}$. The hexagonal morphology, consistent with c-axis oriented ZnO having a wurtzite structure, can be clearly identified in the image of the film surface. The films deposited at 600 and $650{ }^{\circ} \mathrm{C}$ (Figure 2e,e', respectively) look much smoother than the film deposited at $550^{\circ} \mathrm{C}$, and the cross-sections reveal that the films are highly dense. Interestingly, the grains visible in the FESEM images for films deposited at 600 and $650{ }^{\circ} \mathrm{C}$ have irregular shapes, and the grain boundaries as observed on the film surface are not straight lines with $120^{\circ}$ angle at triple junctions, as expected by the rule of minimizing the surface energy ${ }^{20}$; this observation is discussed later in the text.

To understand the faceting behavior seen in the film deposited at $550{ }^{\circ} \mathrm{C}$, two additional ZnO films were deposited under sputtering conditions, which differ from those typically used in this study (80 W constant deposition power at various substrate temperatures). One film was deposited at high temperature $\left(650^{\circ} \mathrm{C}\right)$ and high power $(140 \mathrm{~W})$, and the other was deposited at a lower temperature $\left(450^{\circ} \mathrm{C}\right)$ and low power $(27 \mathrm{~W})$. The resulting film morphologies reveal ed by FESEM on film surface and cross-section are presented in Figure 3.

The film deposited at high temperature and power shows the same faceting features ( $F$ igure $3 a, a^{\prime}$ ) as seen in the sample deposited at $550{ }^{\circ} \mathrm{C}$ and $80 \mathrm{~W}$ power on the target ( $F$ igure $2 \mathrm{~d}, \mathrm{~d}^{\prime}$ ). I I contrast, the film deposited at lower temperature and power does not exhibit a clear faceting on the surface (F igure $3 \mathrm{~b}$ ). H owever, an onset of faceting can be seen, especially in the cross-section image ( $F$ igure $\left.3 b^{\prime}\right)$. These findings suggest that choosing the optimum substrate temperature/sputtering power combination could efficiently control the faceting mechanism. 

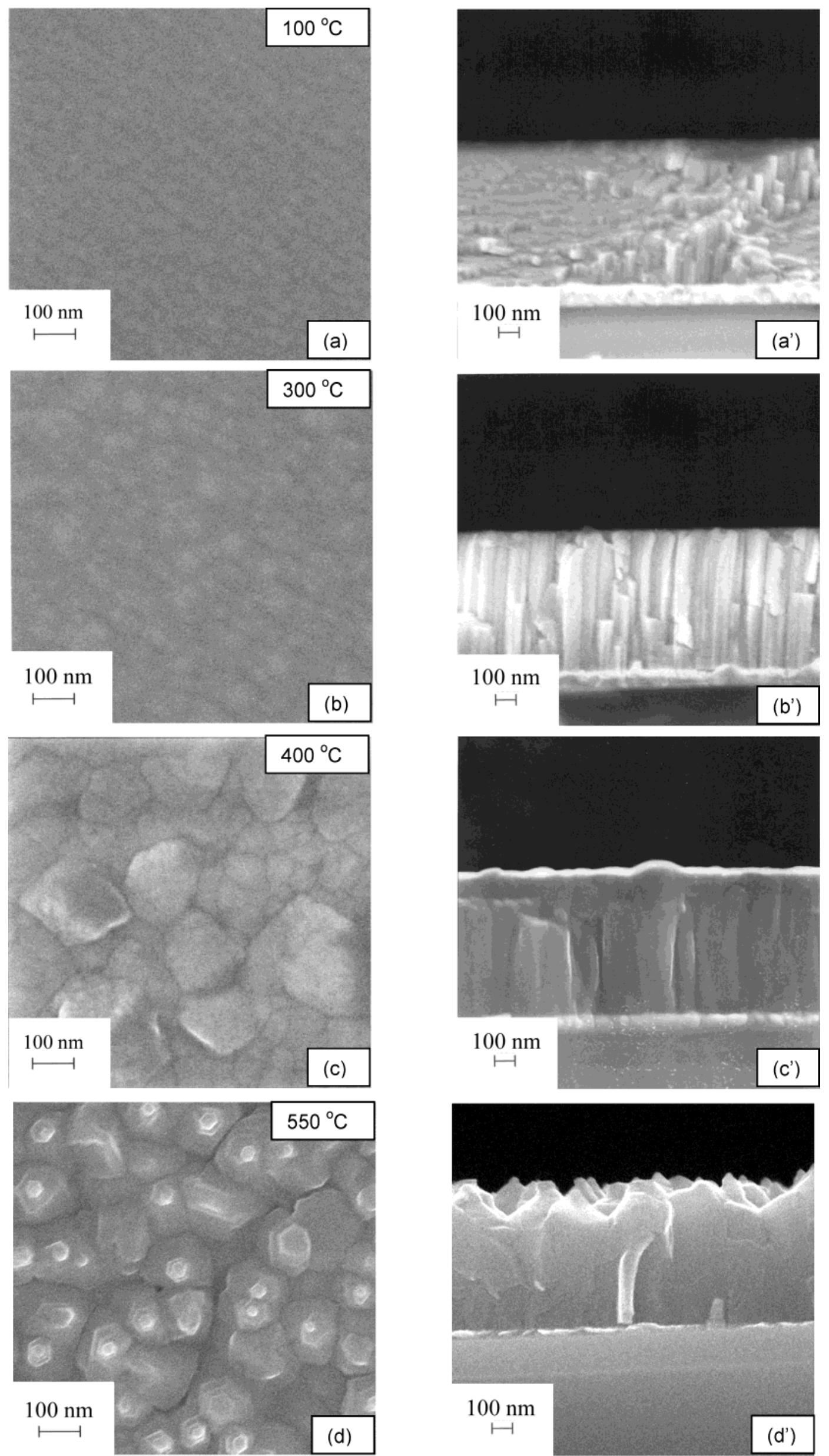

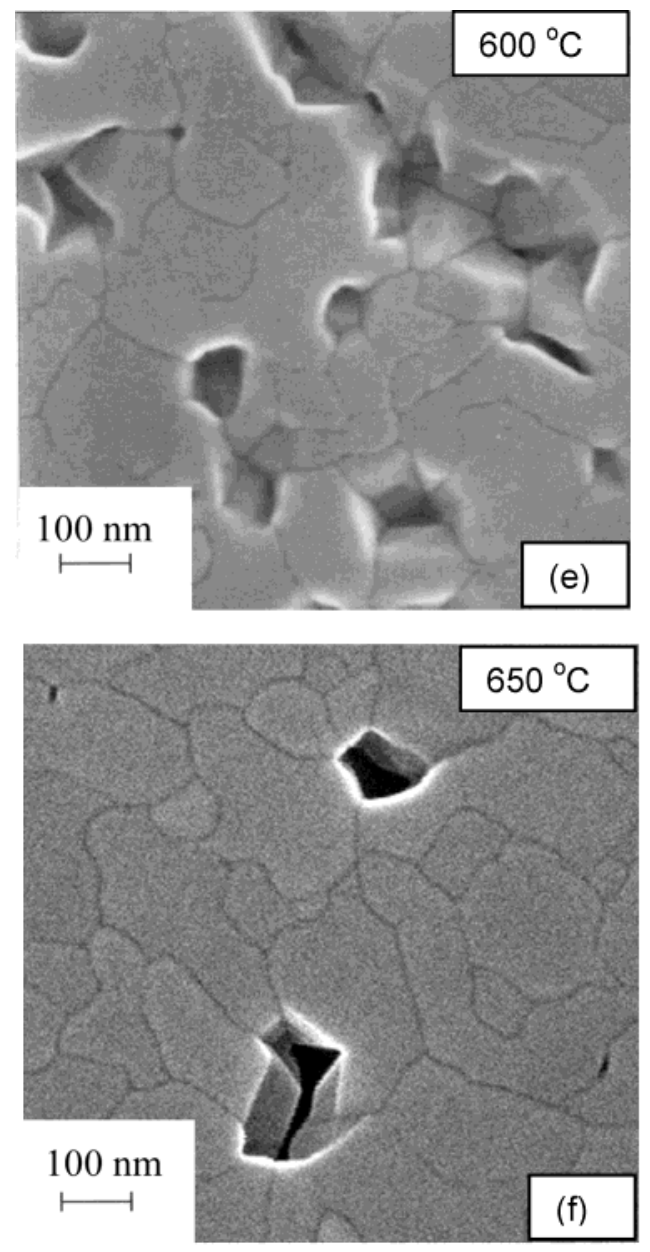
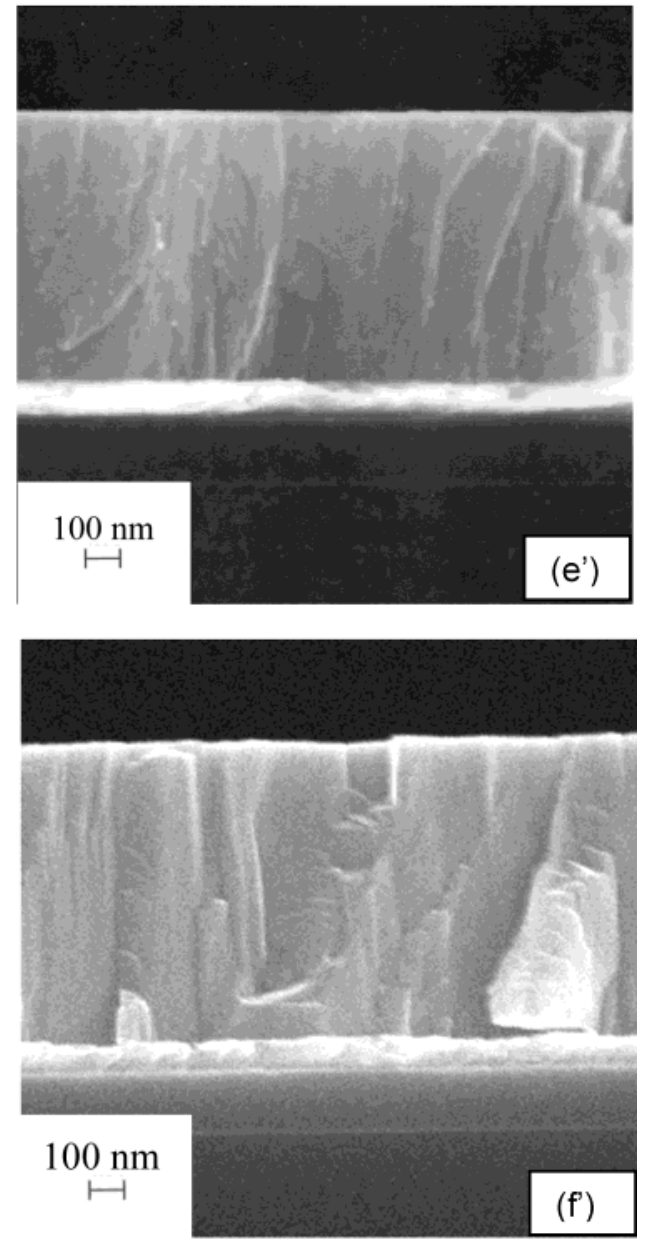

Figure 2. FESEM mi crographs of ZnO film surface and cross-section deposited on Pt (111) coated substrates at different substrate temperatures $\left(p_{\text {total }}=5 \mathrm{mTorr}\right.$, deposition rate $=0.38 \mu \mathrm{m} / \mathrm{h}$ ).

ZnO films deposited on Si with native oxide developed a different morphology as compared with the films deposited under the same conditions but on (111) textured Pt. The FESEM micrograph of the film surface presented in Figure 4a shows a much rougher surface, and the cross-section image in Figure 4a' shows a less dense film than the film deposited on textured Pt under the same processing conditions. This suggests that there is a strong correlation between the morphology of the deposited film and the nature of the substrate.

A TEM investigation of a cross-sectioned specimen deposited at room temperature clearly shows the columnar structure of the film, as seen in Figure $5 \mathrm{a}$. The columnar grains are not perfect single crystals; the grains have a large number of stacking faults that were easily observed in bright- and dark-field images. The contrast differences result from slight variations in structural orientation, which locally change the Bragg diffracting condition. The columnar grains have widths of $40-50 \mathrm{~nm}$ estimated from FESEM and TEM images and length equal to the film thickness.

The micrograph in Figure $5 b$ shows rotational Moiré patterns. Moiré patterns form from the interference between two sets of fringe patterns with similar periodicities. ${ }^{21}$ The grain boundaries that definethe columns are normal to the substrate surface, and the column width is $40-50 \mathrm{~nm}$. No amorphous or equiaxed layer is observed at the interface with Pt. The micrograph also reveals that the grains of the film deposited at room temperature show a high degree of disorder. The lines predominately lying in planes normal to the column growth direction are associated with planar defects, particularly stacking faults with a separation between faults of approximately $10 \mathrm{~nm}$. It is important to note that these types of stacking faults do not change the polarity and hence do not influence the piezoelectric performance of the film.

The analysis of electron diffraction patterns yields information about the crystallinity, orientation, and also about the presence of defects in the $\mathrm{ZnO}$ films. An electron diffraction pattern from the film deposited at room temperature is presented in Figure 6, and the inset shows the area selected for diffraction. The spot patterns show that the film is crystalline and preferentially oriented. The pattern shows additional reflections situated symmetrically around the primary spot that do not belong to a basic ZnO pattern. Due to the large area of the sample exposed to the el ectron beam, multiple grains are diffracting simultaneously. The observed diffraction pattern can be described by several grains oriented with fiber texture. It is also possible that additional reflections are caused by diffraction from stacking faults or double diffraction. ${ }^{21}$

The film deposited at $600{ }^{\circ} \mathrm{C}$ exhibits a dramatically different morphology observed by TEM than the film deposited at room temperature, as seen in Figure 7. The 

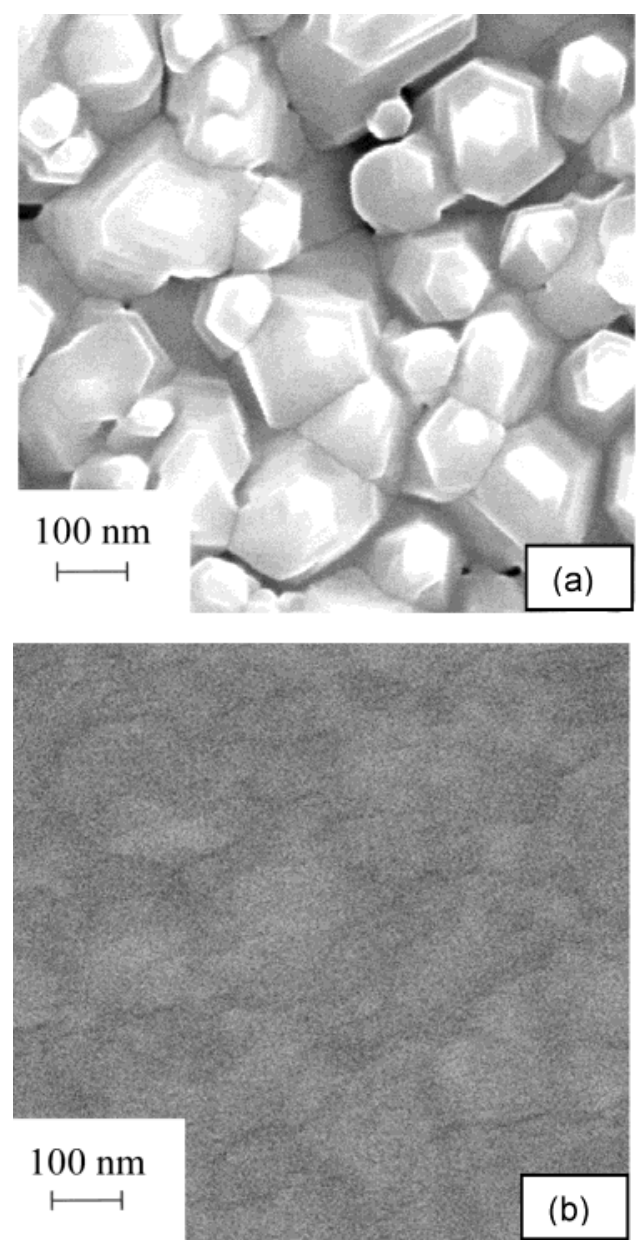
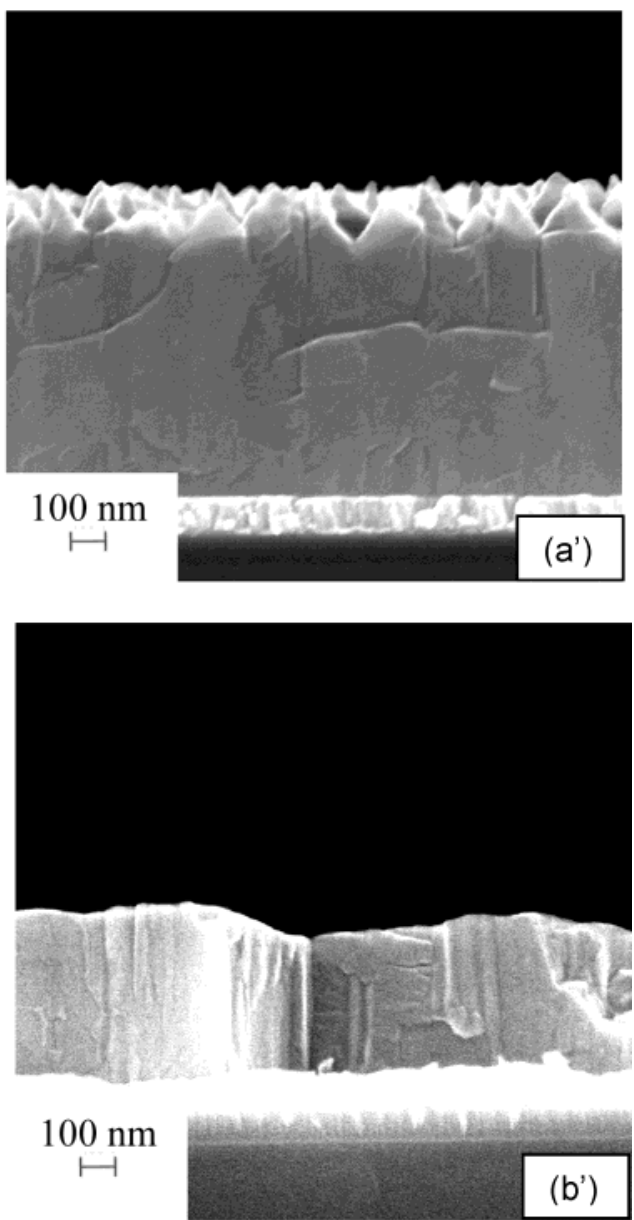

Figure 3. FESEM micrographs of $\mathrm{ZnO}$ thin film surface and cross-section deposited on Pt (111) at $650{ }^{\circ} \mathrm{C} / 140 \mathrm{~W}$ (high power) (a and $a^{\prime}$, respectively) and $450^{\circ} \mathrm{C} / 27 \mathrm{~W}$ (low power) (b and b', respectively).
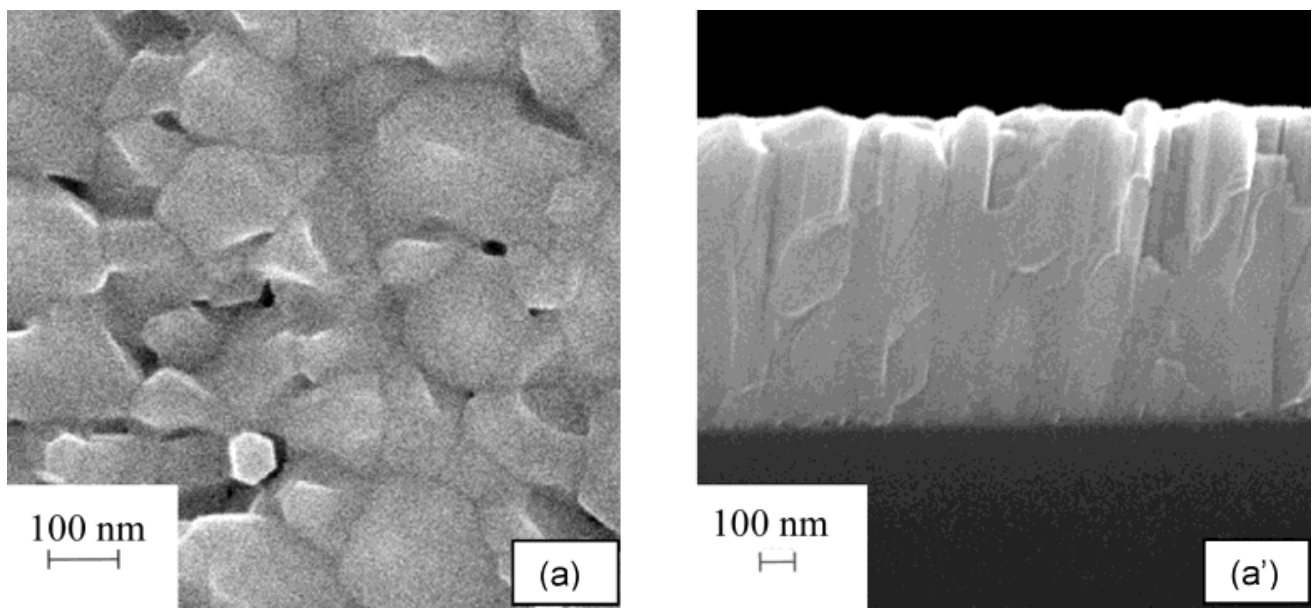

Figure 4. FESEM micrograph of ZnO film surface (a) and cross-section (a') deposited on (100) Si substrates at $650{ }^{\circ} \mathrm{C}$; the film has a rough surface and lower density than film deposited on (111) Pt.

film shows a lower density of defects than the film deposited at room temperature. The stacking faults, if any, do not show as in the film deposited at room temperature. The wavy features observed in Figure 7 are likely to originate from the presence of dislocations. A dislocation produces distortion from the perfect crystal arrangement and has an associated elastic displacement field. Therefore, the Bragg condition for diffraction is locally deviated, and accordingly, the image of the dislocation has a depression in intensity. 22 Thus, dis- locations appear as dark curved lines and exhibit a dark contrast relative to the matrix.

Selected area electron diffraction patterns of $\mathrm{ZnO}$ film deposited at $600{ }^{\circ} \mathrm{C}$ are presented in Figure 8. Since the grain size for this film is larger, the area for diffraction could be selected to cover one grain, as seen in the inset. One can readily see that the patterns are similar to the film deposited at room temperature.

The mechanism described next for the morphological evolution of $\mathrm{ZnO}$ thin films deposited in this study is 

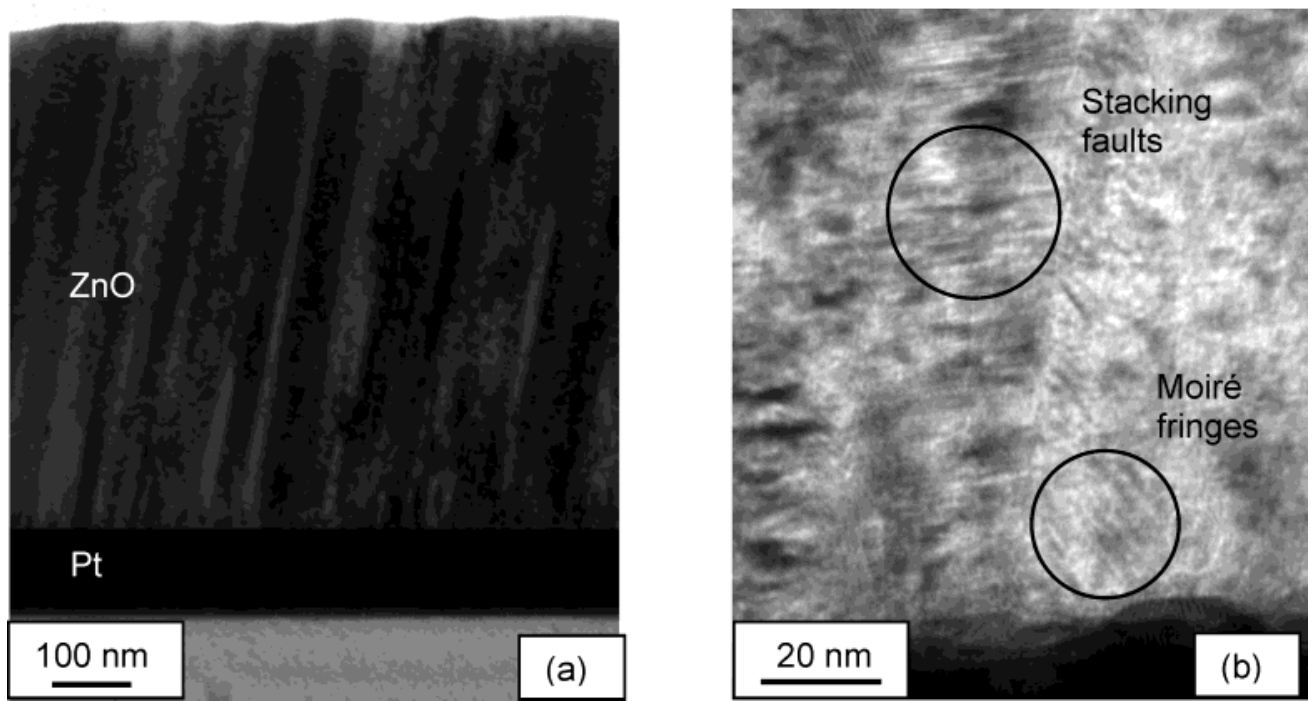

Figure 5. Cross-section TEM of ZnO film deposited at room temperature. (a) Field of view and (b) higher magnification of the film-substrate interface.

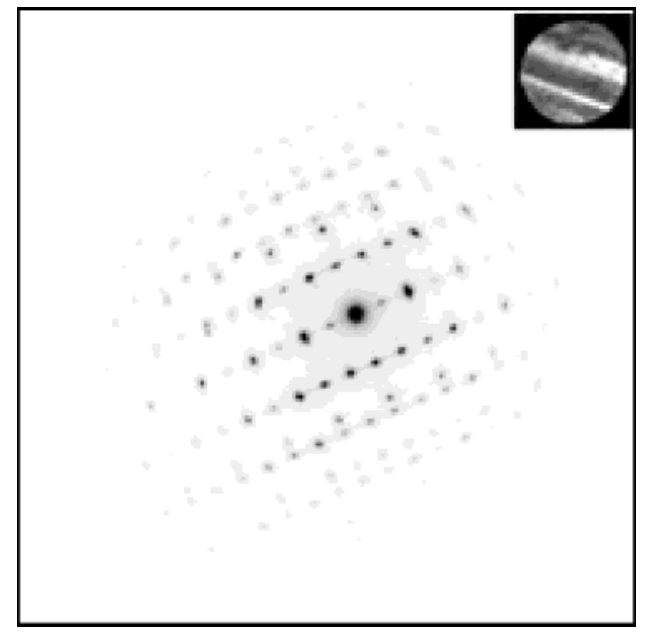

Figure 6. Electron diffraction patterns for film deposited at room temperature on (111) textured Pt; the inset shows the area selected for electron diffraction.

based primarily on surface diffusion. For bulk crystals, minimization of the surface energy is the driving force for evolution of crystalline morphology. Hence, in equilibrium conditions, if there is no influence of epitaxy between the film and the substrate, the films exhibit self-texture and grow with the crystallographic plane of the lowest free energy (i.e., the plane with the closest packing of atoms, the highest reticular density) parallel to the surface. $\mathrm{ZnO}$ tends to grow c-axis-oriented normal to the substrate since the minimization of the surface energy favors the texture along the [0001] direction.

Due to the high energy of impingement of sputtered species, equilibrium conditions may not domi nate morphol ogical evolution. We have found for $\mathrm{ZnO}$ films that the morphological evolution can be described by a mechanism mediated by surface diffusion.

The deposition rate, $R$, is linearly proportional to the power, $\mathrm{P}$, applied to the sputter gun under moderate power limits, which assumes a linear increase in sputtering yield with voltage. ${ }^{23}$ The expression is

$$
P=a R
$$

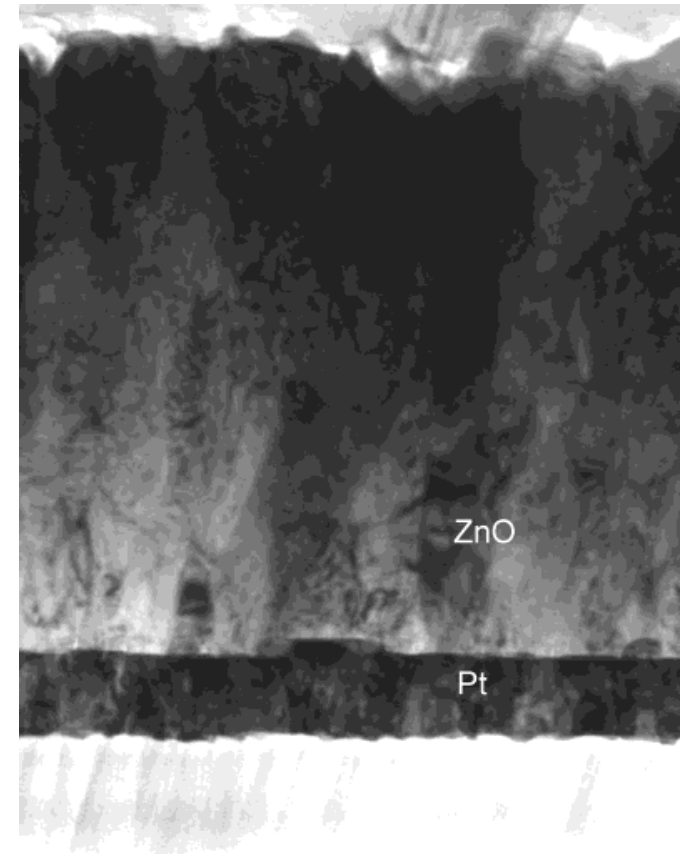

Figure 7. Cross-section TEM micrographs of $\mathrm{ZnO}$ thin film deposited at $600{ }^{\circ} \mathrm{C}$ on (111) textured Pt. (The field of view is $1.2 \times 0.9 \mu \mathrm{m}$.)

where $\mathrm{a}$ is a proportionality constant. Relating the deposition rate to deposition time can be described in terms of the surface coverage, $\theta$, in units of atoms/unit area

$$
\mathrm{R}=\theta \mathrm{A} / \mathrm{t}
$$

where $A$ is the surface area, and $t$ is time. Assuming that the morphology is determined by the surface displacement of an adatom before freezing into place by subsequent adatoms (the degree of surface coverage is arbitrary; however, when a full monol ayer is deposited, further surface diffusion is minimal), the surface displacement, $x$, can be related to time via surface diffusion

$$
x=b(D t)^{1 / 2}
$$




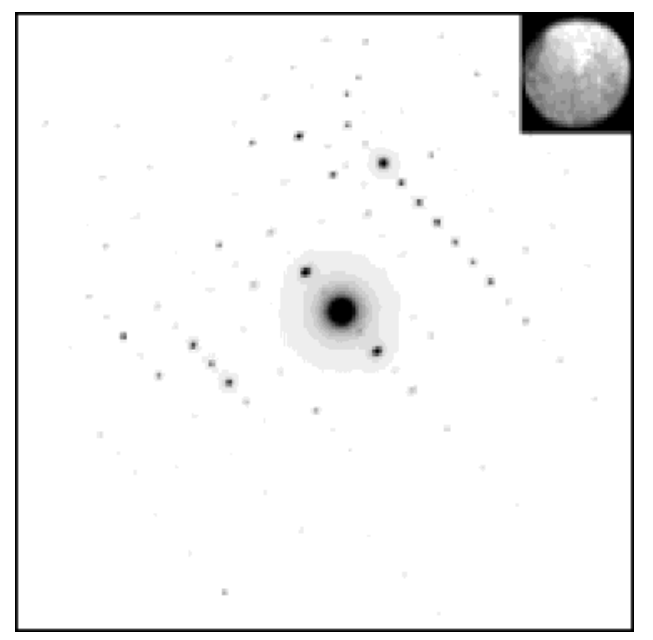

Figure 8. Electron diffraction patterns of $\mathrm{ZnO}$ thin film deposited at $600{ }^{\circ} \mathrm{C}$; the inset shows the area selected for diffraction.

where $b$ is a unitless proportionality constant usually in the range of $2-4$, and $D$ is the surface diffusion constant. Finally, to relate the substrate temperature to power, surface diffusion in this case is assumed to be a thermally activated process that fol lows Ahrrenius behavior; therefore

$$
\mathrm{P}=\mathrm{C} \exp \left(-\mathrm{E}_{\mathrm{A}} / \mathrm{kT}\right)
$$

where $E_{A}$ is the activation energy for surface diffusion, $\mathrm{k}$ is Boltzmann's constant, $\mathrm{T}$ is temperature, and $\mathrm{C}$ is a constant that equals $a b^{2} \theta A D_{0} / x^{2}$, where $D_{0}$ is the preexponential factor for surface diffusion.

On the basis of the expression in eq 4, the activation energy for surface diffusion is calculated to be $0.37 \mathrm{eV}$ from two films that demonstrate complete hexagonal prismatic termination under low power, low temperature conditions $\left(80 \mathrm{~W}, 550{ }^{\circ} \mathrm{C}\right)$ and high power, high temperature conditions $\left(140 \mathrm{~W}, 650^{\circ} \mathrm{C}\right)$. Comparison with literature values for the activation energy of surface diffusion illustrates significant variation. Typical surface diffusion activations are the following: $\mathrm{Si}$ on $\mathrm{Si}(001), 0.67 \mathrm{eV} ;{ }^{24}$ surface grooving of $\mathrm{CaTiO}_{3}, 3 \mathrm{eV} ; 25$ and neck curvature of $\mathrm{Al}_{2} \mathrm{O}_{3}, 5 \mathrm{eV} .{ }^{26}$ The activation of bulk diffusivity for $\mathrm{O}$ in $\mathrm{ZnO}$ is reported to be approximately 2 and $4 \mathrm{eV}$ for two different $\mathrm{ZnO}$ single crystals. ${ }^{27}$ Typically in metals, surface diffusion is roughly $2 / 3$ of the bulk diffusion activation; therefore, it is likely that surface diffusion of $\mathrm{O}$ on $\mathrm{ZnO}$ can be less than $2 \mathrm{eV}$. However, there are limitations to quantification from observed microstructures. Close examination of the two films described above reveals that the microstructure is not exactly identical. Therefore, power and temperature conditions to fabricate identical microstructures are subjective to visual inspection. Additionally, some kinematic energy is transferred to the deposited species due to the sputtering process, further deviating from the assumption that the surface diffusion is only a thermally activated process. Given these limitations, it is still remarkable that surface diffusion (thermally activated and kinematically enhanced) can be characterized for sputtered films simply by examining the microstructure nondestructively after deposition.

This model takes into consideration the competition between atomic mobility, flux of incoming particles (deposition rate), and rates of nucleation and crystalline growth. It has been well-recognized that at low deposition temperatures the film microstructure is determined by the combined effect of atom shadowing and limited atomic mobility. Under these conditions, the simplified ballistic deposition model first introduced by $\mathrm{Vold}^{28}$ and later refined by Ramanlal and Sander ${ }^{29}$ gives a reasonable view of film microstructure evolution. According to this model, the sputtered particles from the target are added one by one on the substrate foll owing trajectories with the substrate in a line-of-sight impingement. Due to limited adatom mobility at low substrate temperatures, the particles adhere irreversibly on the landing site. In this case, the sticking coefficient is close to 1 , neglecting backsputtering. The peaks formed in this way on the film shadow the valleys, which leads to an increasing roughness and low density of the film. The ZnO films deposited at temperatures between room temperatureand $300{ }^{\circ} \mathrm{C}$ devel op intercolumnar porosity, which is an indicator of morphological evolution characteristic of low atomic mobility. As a competing mechanism at high substrate temperatures, the surface diffusion process leads to an erosion of peaks that formed due to geometrical shadowing and filling of valleys. If the deposition rate is low enough, there is sufficient time for the deposited atoms to diffuse on the surface before being frozen into place by other incoming particles. The films in this case are smooth, as seen in Figure 2e,e', and dense, and the boundaries between columns are not easily identified. The energy needed for diffusion on the surface is regulated by the thermal energy delivered to the substrate by intentional heating.

The pitted surface observed in the film deposited at high temperatures, 600 and $650{ }^{\circ} \mathrm{C}$ (Figure 2e,f) is, however, the result of still limited surface diffusion. The pit density decreases with increasing deposition temperature since the adatom mobility increases with temperature, and the atoms have greater kinetic energy to diffuse on the surface. Since the mobility of atoms on the surface greatly exceeds that in the bulk for $\mathrm{T}<$ $0.5 \mathrm{~T}_{\mathrm{m}}$, where $\mathrm{T}_{\mathrm{m}}$ is the melting point, the interior of the film is kinetically frozen, and all microstructural development occurs at the free surface. These observations suggest that increasing the particle (or adatom) energy, as achieved by increasing the deposition rate, and decreasing the substrate temperature will have similar effects on film morphology.

The bimodal morphology seen in the film deposited at $450{ }^{\circ} \mathrm{C}$ is a consequence of enhancement of grain boundary mobility, which is, however, structure-sensitive. Therefore, only a subset of grain boundaries is mobile at a given temperature al lowing certain grains to evolve with a higher rate than others. ${ }^{30}$ Grain boundary movement is an important process in the evolution of thin film microstructure and occurs at anomalously low temperatures relative to bulk material. ${ }^{31}$

An interesting case of morphological evolution is surface faceting, which is very pronounced in the film deposited at $550{ }^{\circ} \mathrm{C}$. The parameters influencing faceting and texture development are the following: properties of the sputtered atoms (i.e., the kinetic energies and the angles of the sputtered atom trajectories), the potential energies of atoms at the surface of the film, 
the binding energy of adatoms on different crystal faces, the surface free energies of different crystal planes, and the surface diffusion rates on different crystal faces..$^{35,36}$ $\mathrm{ZnO}$ morphology is dominated by four faces: (0001), $(10 \overline{1} 0)$, $(11 \overline{2} 0)$, and $(000 \overline{1})$. There has been reported densities of the surface energy for (0001), (112̄0), and (1010) planes in ZnO as 0.099, 0.123, and $0.209 \mathrm{eV} / \AA^{2}$, respectively ${ }^{15}$. These values suggest that the (0001) plane has the fastest growth rate; hence, it disappears first from the growth mode. Only surfaces with low growth rates can form facets as typically observed in crystal growth experiments. It can be concluded therefore that the (0001) plane does not facet in equilibrium conditions. The following relationship between the growing rates, v, of different crystallographic planes has been reported ${ }^{32}$

$$
\mathrm{v}(0001)>\mathrm{v}(01 \overline{1} 0)>\mathrm{v}(000 \overline{1})
$$

This study showed that faceting behavior of $\mathrm{ZnO}$ films can be efficiently controlled by simultaneously controlling the substrate temperature and the energy of the incoming species. This finding confirmed our mechanistic model. If the film was deposited under high power and high substrate temperature, such as the film with morphology shown in Figure $3 a, a^{\prime}\left(650^{\circ} \mathrm{C} / 140 \mathrm{~W}\right)$, the higher deposition rate overcame the enhanced surface diffusion, and facets could form. In contrast, films deposited at lower power ( $27 \mathrm{~W}$ ) and lower substrate temperature $\left(450^{\circ} \mathrm{C}\right)$, shown in Figure $3 \mathrm{~b}$, did not show surface faceting. In this case the deposition temperature, although not high, provided enough mobility to the particles to move on the surface before being buried under a new incoming flux of particles that was about $20 \%$ of the flux for the specimen in Figure 3 a. However, an onset of faceting is readily observed in the crosssection micrograph presented in Figure 3b'. Therefore, the deposition conditions have not fully satisfied the desired imbalance between the two sources of energy on the substrate, and faceting could not develop. This suggests that either raising the deposition ratefor a film deposited at $450{ }^{\circ} \mathrm{C}$ or lowering the substrate temperature for a film deposited at $27 \mathrm{~W}$ would promote faceting. If an experimental Wulff plot ${ }^{33}$ would be available for the temperature range of interest for this study, it would be possible to predict which crystallographic planes would be more stable and thus lead to faceting in $\mathrm{ZnO}$.

As mentioned earlier in the text, irregular shapes of grain boundaries seen in films deposited at high temperatures, 600 and $650{ }^{\circ} \mathrm{C}$ on (111) textured Pt (Figure $2 \mathrm{e}, \mathrm{f})$, can be explained considering that grains grow with different rates. When two neighboring grains nucleate simultaneously and grow together at an identical rate, they impinge al ong a straight line that is perpendicular to the bisector of the line joining the nucleation points. ${ }^{34}$ It was found by computer simulation that if the two grains nucleate at different times and grow with different rates, the grain boundaries are not straight lines. ${ }^{34}$ Moreover, grains with a larger size will grow at the expense of their neighbors. Considering that the growth rate increases steadily with the grain radius, the larger grains will eventually surround and enclose the smaller grains that have a lower growth rate. This microstructure evolution mechanism can overlap with that of the grain boundary migration. If the larger grains are surrounded by grain boundaries that have a higher mobility than other grain boundaries in the structure, the irregular shape of the grain boundaries is even more enhanced. However, due to their curvature, the irregular grain boundaries observed in the films deposited in this study at temperatures of 600 and 650 ${ }^{\circ} \mathrm{C}$ are evidently in nonequilibrium. Therefore, upon heating, their evolution toward the equilibrium shape is expected.

The substrate has a marked influence on $\mathrm{ZnO}$ film nucleation and grains evolution, influencing the crystalline growth with its nature (textured vs amorphous) and chemical behavior (oxidizing vs nonoxidizing). It is obvious that the substrate nature influences the early stages of film development, which in turn determines the further evolution of film morphology and texture. When deposited on unetched Si possessing a native amorphous $\mathrm{SiO}_{2}$, the $\mathrm{ZnO}$ film is forced to self-nucleate. Therefore, due to the amorphous nature of the nucleating surface, the first few atomic layers of the $\mathrm{ZnO}$ film are randomly oriented, and the preferred orientation along [0002] direction is gained later in the process, 35 when the film thickness develops. This is the case of evolutionary growth texture. ${ }^{36} \mathrm{ZnO}$ deposited on textured Pt (111) behaves differently. Platinum, which has a face-centered-cubic structure, does not readily oxi dize on the surface. Moreover, the (111) crystallographic plane of Pt has a hexagonal array of atoms. This atomic array allows hexagonal $\mathrm{ZnO}$ to nucleate al ong the [0002] direction, determining therefore an enhanced film texture. This is the case of activated nucleation texture, ${ }^{36}$ in which the textured substrate activates the texture development for the deposited film. Typically, oxideforming metals such as $\mathrm{Al}$ or $\mathrm{Ti}$ contain a thin layer of amorphous native oxide. When deposited on such substrates, ZnO must self-nucleate, similar to deposition on unetched Si. The film texture is usually less developed than in the case of films grown on nonoxide forming substrates.

An important factor that has to be considered in explaining the microstructure development of $\mathrm{ZnO}$ is the roughness of the substrate on which the $\mathrm{ZnO}$ film is deposited. On a rough surface, the mechanism of texture development is modified. The crystallographic orientation factor is shadowed in this case by the geometric orientation. The substrate roughness offers a large number of randomly oriented nucleation sites. Therefore, although the film may be locally oriented with the $c$-axis normal to the substrate within the undulation of the surface roughness, the overall orientation would display a broad rocking curve due to a range of crystallite orientations with respect to the substrate surface. However, the average roughness of (111) Pt on which the $\mathrm{ZnO}$ thin films were deposited in this study was $\mathrm{R}_{\mathrm{a}}$ $=5 \AA$ and a peak-to-valley height of $30 \AA$ as measured by near-field scanning optical microscopy.

In both textured and/or amorphous substrates, the substrate temperature and the deposition rate are the chief variables influencing the evolution of the film microstructure. Considering that the deposition rate was approximately constant in our experiments, the substrate temperature remains the dominant variable 
in determining the morphology of $\mathrm{ZnO}$ films deposited on a given substrate.

\section{Conclusions}

In this paper, we have shown the possibility of depositing by reactive sputtering $\mathrm{ZnO}$ thin films with different morphological features, depending on deposition parameters, especially substrate temperature and substrate type.

The main conclusions can be summarized as follows: (i) The surface morphology of the $\mathrm{ZnO}$ films is strongly dependent on the substrate temperature and its nature (oxide forming vs nonoxide forming substrate), if the deposition rate is maintained constant. The films show enhanced crystallinity and texture when deposited on textured nonoxide forming substrate (i.e., Pt (111)) than when deposited on amorphous substrate and when deposited at temperatures higher than $500{ }^{\circ} \mathrm{C}$.

(ii) Film deposited at room temperature has a high density of stacking faults lying in planes normal to the growth direction as seen by TEM cross-section analysis, whereas film deposited at $600^{\circ} \mathrm{C}$ shows the presence of dislocations. The electron diffraction patterns show that the films are highly oriented.

(iii) A mechanistic model involving the interplay between atomic mobility, flux of incoming particles (deposition rate), and rates of nucleation and crystalline growth was proposed.

Acknowledgment. The authors wish to thank $\mathrm{Dr}$. Mark Vaudin from the National Institute of Standards and Technol ogy for the rocking curve data analysis, to Prof. Matthew Libera from Stevens Institute of Technology for the help with TEM analysis and J ohn Grazul from Lucent Technologies for TEM sample preparation. Near-field scanning optical microscopy was gratefully performed by Luis Garfias. E. Mirica also acknowledges the Stevens I nstitute of Technology, Agere Systems, and Lucent Technologies for support during the project.

\section{References}

(1) Schropp, R. E. I.; Madan, A. J . Appl. Phys. 1989, 66 (5) 2027-2031.

(2) Heideman, R. G.; Lambeck, P. V.; Gardeniers, J . G. E. Opt. Mater. 1995, 4 (6), 741

(3) Penza, M.; Martucci, C.; Anisimkin, V. I.; Vasanelli, L. Mater. Sci. Forum 1996, 203, 137.

(4) Hutchins, M. G. C. Figures, In Energy and Environment; Pergamon: Oxford, 1990; 3, 1398.

(5) Sang, B.; Yamada, A.; Konagai, M. J pn. J . Appl. Phys. 1998, 37 (2B), L206.

(6) Purica, M.; Budianu, E.; Rusu, E. Microelectron. Eng. 2000, $51-52(1-4), 425$.

(7) Huang, M.; Mao, S.; Feick, H.; Yan, H.; Wu, Y.; Kind, H.; Weber, E.; Russo, R.; Yang, P. Science 2001, 292, 1897.

(8) Ohmoto, A.; Kawasaki, M. IEICE Trans. Electron. 2000, E 83-C (10), 1614.
(9) Emanetoglu, N. W.; Gorla, C.; Liu, Y.; Liang, S.; Lu, Y. Mater. Sci Semicond. Proc. 1999, 2, 247.

(10) Von Pressing, F. J .; Zeng, H.; Kim, E. S. Smart Mater Struct. 1998, 7, 396.

(11) Martin, P. M.; Good, M. S.; J ohnson, J . W.; Posakony, G. J .; Bond, L. J .; Crawford, S. L. Thin Solid Films 2000, 379, 253.

(12) D. F. Nelson, D. F. Landolt-Bornstein: Low-Frequency Properties of Dielectric Crystals; Springer-Verlag: Berlin, 1993; p 107.

(13) Kamiya, T. J pn. J . Appl. Phys. 1996, 35, 4421.

(14) Yoshino, Y.; Inoue, K.; Takeuchi, M.; Ohwada, K. Vacuum 1998, 51 (4), 601

(15) F ujimara, N.; Goto, S.; I toa, T. Mater. Res. Soc. Symp. Proc. 1992, 263, 187.

(16) Verghese, P. M.; Clarke, D. R. J . Mater. Res. 1999, 14 (3), 1039.

(17) Commercial equipment is identified to adequately describe the experimental procedure; this does not imply a recommendation or endorsement by NIST, nor does it imply that the equipment is necessarily the best available for the purpose.

(18) Vaudin, M. D.; Rupich, M. W.; J owett, M.; Riley, G. N.; Bingert, J. F. J. Mater. Res. 1998, 13, 2910 (software download available at http://www.ceramics.nist.gov/webbook/TexturePlus/texture.htm).

(19) Vaudin, M. D.; 12th International Conference on Texture of Materials; National Research Council of Canada Research Press: Ottawa, 1999; pp 186-191.

(20) Kingery, W. D.; Bowen, H. K.; Uhlmann, D. R. Introduction to Ceramics, 2nd ed.; J ohn Wiley \& Sons: 1976; p 212.

(21) Williams, D. B.; Carter, C. B. Transmission Electron Microscopy III-Imaging; Plenum Press: New York, 1996.

(22) Romig, A. D. In Analytical Transmission Electron Microscopy, ASM Handbook; Whan, R. E., Ed.; ASM International, Materials Park, OH, 1986; Vol. 10, p 429.

(23) Lamont, L. T., J r.; Turner, F. T. J . Vac. Sci. Technol. 1974, $11(1), 47$.

(24) Mo, Y.-W.; Kleiner, J .; Webb, M. B.; Lagally, M. G. Surf. Sci. 1992, 268, 275.

(25) Ceh, M.; Kolar, D. J . Mater. Sci. 1989, 24 (12), 4307.

(26) Sajgalik, P.; Panek, Z.; Uhrik, M. J . Mater. Sci. 1987, 22 (12), 4460.

(27) Tomlins, G. W.; Routbort, J . L.; Mason, T. O. J . Am. Ceram. Soc. 1998, 81 (4), 869

(28) Vold, M. J . J . Colloid Sci. 1959, 14, 168.

(29) Ramanlal, P.; Sander, L. M. Phys. Rev. Lett. 1985, 54 (6), 1828.

(30) Ohring, M. The Materials Science of Thin Films; Academic Press: New York, 1992.

(31) Smith, D. A.; I brahim, A. Mater. Res. Soc. Symp. Proc. 1994, 317,401

(32) Li, W.-J .; Shi, E.-W.; Zhong, W.-Z.; Yin, Z.-W. J . Cryst. Growth 1999, 203, 186.

(33) Blakely, J. M. Introduction to the Properties of Crystal Surfaces; Pergamon Press Inc.: New York, 1973; p 15.

(34) Frost, H. J .; Thompson, C. V. J . Electron. Mater. 1988, 17 (5), 447.

(35) Matsuoka, M.; Ono, K. Appl. Phys. Lett. 1988, 53, 1393.

(36) Barna, P. B.; Adamik, M. Science and Technology of Thin Films; World Scientific Publishing Co. Pte. Ltd.: Singapore, 1995; p 1.

CG025595] 